\title{
Fall speed measurement and high-resolution multi-angle photography of hydrometeors in free fall
}

\author{
T. J. Garrett ${ }^{1}$, C. Fallgatter ${ }^{1}$, K. Shkurko ${ }^{1}$, and D. Howlett ${ }^{2}$ \\ ${ }^{1}$ Department of Atmospheric Sciences, University of Utah, Salt Lake City, Utah, USA \\ ${ }^{2}$ Alta Center for Snow Science, Alta, Utah, USA
}

Correspondence to: T. J. Garrett (tim.garrett@utah.edu)

Received: 8 June 2012 - Published in Atmos. Meas. Tech. Discuss.: 13 July 2012

Revised: 10 October 2012 - Accepted: 16 October 2012 - Published: 5 November 2012

\begin{abstract}
We describe here a new instrument for imaging hydrometeors in free fall. The Multi-Angle Snowflake Camera (MASC) captures high-resolution photographs of hydrometeors from three angles while simultaneously measuring their fall speed. Based on the stereoscopic photographs captured over the two months of continuous measurements obtained at a high altitude location within the Wasatch Front in Utah, we derive statistics for fall speed, hydrometeor size, shape, orientation and aspect ratio. From a selection of the photographed hydrometeors, an illustration is provided for how the instrument might be used for making improved microwave scattering calculations. Complex, aggregated snowflake shapes appear to be more strongly forward scattering, at the expense of reduced back-scatter, than heavily rimed graupel particles of similar size.
\end{abstract}

\section{Introduction}

Despite dramatic progress in numerical weather prediction over the past several decades, a long-standing Achilles heel of mesoscale forecasting models has been their representations of precipitation microphysics (e.g., Lin et al., 1983; Rutledge and Hobbs, 1984; Reisner et al., 1998). Microphysical processes are complicated to simulate, while modeled storm lifetime and precipitation rates are exquisitely sensitive to what types of hydrometeors form, and how fast they grow and fall (Garvert et al., 2005; Colle et al., 2005; Milbrandt et al., 2010).

Hydrometeor form also becomes relevant for calculations of hydrometeor electromagnetic scattering characteristics that are required for remote sensing applications and microwave communications. Radar measurement is based on the intensity of back-scattering by snowflakes (e.g., Matrosov, 2007; Liu, 2008b), while radiometer measurement is based on the reduction of upwelling microwave energy that is initially emitted by surface and lower atmospheric gases, and then scattered by snowflakes in the atmosphere (e.g., Skofronick-Jackson et al., 2004; Noh et al., 2009). Radio communications signals can be significantly depolarized by precipitation, and attenuation can range up to $3 \mathrm{~dB}$ per kilometer (Oguchi, 1983). Normally, however, existing databases for calculating scattering by precipitation are based on calculations for very idealized hydrometeor forms (Maruyama and Fujiyoshi, 2005; Westbrook et al., 2006; Ishimoto, 2008; Nowell, 2010).

Accurate characterization of hydrometeor shape appears to be essential for accurate representations of both of these two problems. Rimed graupel normally has a terminal fall speed that is much higher than that of spatial aggregates, so that when graupel is diagnosed, it contributes to more rapid simulated desiccation of storms (Colle et al., 2005). With respect to microwave scattering calculations, the minimum computational requirement for discrete dipole scattering calculations is a grid spacing that satisfies

$|n| k d<0.5$

where $n$ is the complex refractive index, $k$ is the wavenumber $(2 \pi / \lambda)$ and $d$ the dipole spacing (Draine and Flatau, 2008). So, for example, lookup tables for a high frequency $183 \mathrm{GHz}$ radiometer $(\lambda=1.6 \mathrm{~mm},|n| \sim 1.78)$, as anticipated for the Global Precipitation Measurement mission, would require snowflake models defined by a mesh finer than at most $72 \mu \mathrm{m}$. 


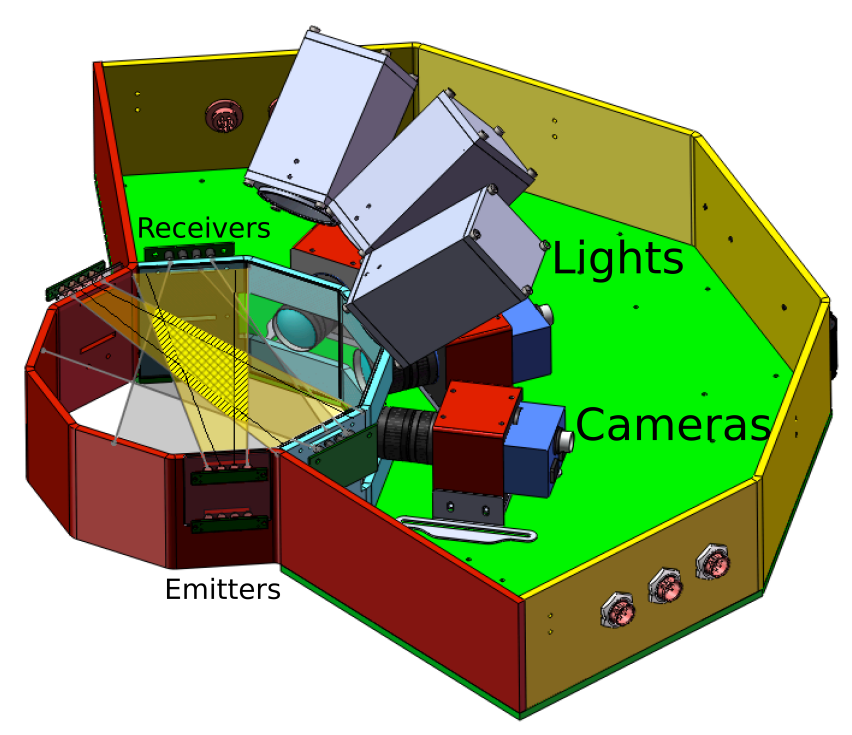

Fig. 1. Schematic of the basic components of the Multi-Angle Snowflake Camera. The hatched region represents the cross section for triggering of the near-infrared motion detector system.

Constraining the problem with empirical data has proved challenging. Traditionally, this has been done through the painstaking manual examination of individual hydrometeors (Locatelli and Hobbs, 1974; Bruintjes et al., 1987; Mitchell et al., 1990; Thériault et al., 2012). Automated ground-based disdrometers have recently helped eliminate human subjectivity and allowed for greater statistical power (e.g., Kruger and Krajewski, 2002; Barthazy et al., 2004; Yuter et al., 2006; Newman et al., 2009; Zawadzki et al., 2010). Nonetheless, these newer instruments require imaging small, complex, fast-moving particles on a laser diode optical array, and this can lead to significant sizing errors (Yuter et al., 2006). Further, the images are normally silhouettes with a very coarse resolution of about $200 \mu \mathrm{m}$, which makes it very difficult to confidently discriminate particle habit (Barthazy and Schefold, 2006). It is impossible to assess the extent of riming from $40 \mu \mathrm{m}$ diameter droplets within silhouetted images at $200 \mu \mathrm{m}$ resolution, or to easily discriminate them from tight clumps of aggregates.

What is needed is a measurement technique that provides automated high-resolution images of hydrometeors in free fall, while simultaneously measuring their fall speed. This paper describes a new instrument with these capabilities, and summarizes a few of the statistical properties of hundreds of thousands of hydrometeors sampled during the winter of early 2012. The article concludes with an illustration of how the instrument might be used to refine microwave scattering calculations by hydrometeors.
Table 1. Lens and camera parameters for the Multi-Angle Snowflake Camera.

\begin{tabular}{lccc}
\hline $\begin{array}{l}\text { Camera } \\
\text { lens/body }\end{array}$ & $\begin{array}{c}\text { Horizontal } \\
\text { field of } \\
\text { view }(\mathrm{mm})\end{array}$ & $\begin{array}{c}\text { Depth of } \\
\text { field at } \\
f / 5.6(\mathrm{~mm})\end{array}$ & $\begin{array}{c}\text { Image } \\
\text { resolution } \\
(\mu \mathrm{m})\end{array}$ \\
\hline $12 \mathrm{~mm} / 1.2 \mathrm{MP}$ & 47 & 15 & 36 \\
$16 \mathrm{~mm} / 1.2 \mathrm{MP}$ & 35 & 10 & 27 \\
$35 \mathrm{~mm} / 5 \mathrm{MP}$ & 22 & 2 & 9 \\
\hline
\end{tabular}

\section{The Multi-Angle Snowflake Camera}

The Multi-Angle Snowflake Camera, or MASC, was developed to address the need for high-resolution multi-angle imaging of hydrometeors in free fall, while simultaneously measuring their fall speed. The instrument was developed out of the University of Utah and is now available through Fallgatter Technologies.

As illustrated in the schematic drawing in Fig. 1, the MASC consists of three cameras, separated by $36^{\circ}$ and each pointing at an identical focal point approximately $10 \mathrm{~cm}$ away. The focal point itself lies within a ring through which hydrometeors fall. The ring houses a system of near-infrared emitter-detector pairs, arranged in two arrays that are separated vertically by $32 \mathrm{~mm}$. Hydrometeors passing through the lower array simultaneously trigger each of the three cameras as well as a bank of lights aimed at the center of the camera depth of field. Fall speed is calculated from the time it takes to traverse the distance between the upper and lower triggering array.

The cameras and lenses are commercially available. The MASC described here was deployed with two Unibrain Fire-i $785 b$ (grayscale) $1280 \times 960$ pixel cameras in the outer positions, and one Unibrain Fire-i 980b (grayscale) $2456 \times 2058$ pixel camera in the center position. The lowerresolution cameras used either $12 \mathrm{~mm}$ Pentax or $16 \mathrm{~mm}$ Fujinon megapixel C-mount lenses. The higher-resolution camera was fitted with a Navitar Megapixel C-mount lens.

Table 1 summarizes the camera parameters, along with their respective values for depth of field and image resolution as determined using a calibration target. Shorter lenses have the disadvantage of lower resolution, but the advantage of a larger depth of field and horizontal field of view. Conversely, the $35 \mathrm{~mm}$ lens begins to approximate the $9 \mathrm{~cm}$ object distance. This "macro" perspective constrains the depth of field with the advantage that the pixel resolution is just $9 \mu \mathrm{m}$. While it might seem that a $16 \mathrm{~mm}$ lens on a $5 \mathrm{MP}$ camera body would offer the optimal mix of high resolution and a large depth of field, this is not in fact the case. Rather, for a fixed lens and digital sensor size, swapping a 1.2 MP body with a 5 MP body merely doubles the field of view while maintaining a constant image resolution in $\mu \mathrm{m}$ units.

The camera exposure time required to capture fine details in falling hydrometeors at close range is extremely short. For 
the results described here, 1/25000th of a second was chosen. This speed is sufficiently fast to capture a vertical resolution of $40 \mu \mathrm{m}$ in a hydrometeor falling at $1 \mathrm{~m} \mathrm{~s}^{-1}$ while allowing for adequate light from the MASC's three 2700 lumen light emitting diodes. LEDs were chosen over a traditional xenon flash system because they require much lower voltages, are longer lived, and are technically easier to implement where images might be collected at a rate of once per second, in cold conditions, and continuously over long periods. Upgrades are underway to enable higher powered and more concentrated light, with the expectation that it will allow for shorter exposure times and larger depths of field.

The near-infrared motion sensor device that is used for triggering the cameras and measuring fall speed has been designed to detect the smallest hydrometeors, whether liquid or ice. Each sensor array contains two near-infrared emitter/detector pairs, with an intersection point that spans the horizontal domain occupied by the camera depth of field. Each emitter/detector pair is based on a set of four nearinfrared LEDs facing four opposite photodiodes. Each emitter subtends a $6^{\circ}$ angle and each photodiode a $15^{\circ}$ viewing angle. The intersection point of the two pairs is highlighted in Fig. 1 , and occupies a maximum cross section of $3100 \mathrm{~mm}^{2}$.

With this setup, a $35 \mathrm{~mm}$ field of view and $10 \mathrm{~mm}$ camera depth of field corresponds to just $11 \%$ of the trigger depth of field, implying that just one in nine photographed images is in sharp focus. As shown in Fig. 1, one option for increasing the in-focus fraction is to physically block part of the lower emitter array. For example, if the two outermost emitters are blocked, then the trigger depth of field is reduced from 3100 to $1400 \mathrm{~mm}^{2}$. This does not change the number of in-focus images collected, but it does reduce the number of images that must ultimately be processed as rejects.

Falling hydrometeors larger than approximately $0.1 \mathrm{~mm}$ in maximum dimension (representing approximately $1 / 100000$ th of the trigger cross section) are detected as a broken beam. The MASC microprocessor electronics are designed to accept only very rapidly varying fluctuations in the detected emission. The goal is to filter out ambient light fluctuations associated with varying sunlight and shadows. The instrument works equally well under all natural lighting conditions, including darkness. The capture interval can be as fast as the hydrometeor interarrival times, or limited to a desired frequency. Here it was set to once per second in order to limit excessive flashes near ski resort employee dormitories.

The fall speed is calculated from the time interval between two successive triggers, vertically separated by $32 \mathrm{~mm}$, which allows only for a trajectory from the top to the bottom of the triggering arrays. The automated calculation is double checked for repeatability and accuracy in the laboratory. This is done by measuring the length of photographed motion blur of a small bead, captured at a slow camera shutter speed.

The MASC microprocessor controls the camera and communications via PC using a FireWire 800 Line for image data and one USB-RS232 Converter for camera control. The camera driver is supplied by Unibrain for use with Microsoft Windows. In-house software has been developed for data acquisition of images, fall speeds, timestamps, and housekeeping variables.

\section{Image analysis}

Analysis of MASC images has been performed using the MATLAB image processing toolbox. Hydrometeors in MASC images occupy only a fraction of the picture frame. The region occupied by the hydrometeor is identified using a Sobel edge detection algorithm, which highlights regions of local gradients. The linear gradients in the frame are dilated by $200 \mu \mathrm{m}$ (or the nearest pixel equivalent) both horizontally and vertically so that an enclosing area can be identified and filled. The area is then eroded horizontally and vertically by the same degree as the dilation. The result is a frame with pixels having a value of 1 for the hydrometeor location and 0 for the background.

Only frames containing a single hydrometeor are considered, provided that less than a linear length of $0.5 \mathrm{~mm}$ of the hydrometeor domain touches the frame edges, and that the maximum pixel brightness is at least 0.2 (or 51 on a scale of 0 to 255). Due to a mismatch between the depth of field for the motion sensor triggers and the depth of field for the camera images, images are normally out of focus.

For the sake of analysis, hydrometeor data are considered in post-analysis only if they passed a focus threshold. There is no foolproof method for automatically distinguishing out of focus images when the particle shapes are not known a priori and they are unpredictably complex. However, we found that out of focus images tend to be relatively dark and lacking in internal gradients. To identify such images, a map is calculated for the standard deviation of pixel brightness, based on a $3 \times 3$ neighborhood around each pixel within the hydrometeor domain. Images are rejected as being out of focus if the mean standard deviation for the hydrometeor domain is less than or equal to 0.02 , or 5 on a scale of 0 to 255 .

If at least two of the three camera images satisfy the above image acceptance criteria, then images are analyzed for a range of properties, averaged over camera perspectives. These properties include the average maximum dimension along the major axis $D_{\max }$, the aspect ratio relative to the minimum dimension along the minor axis $\alpha=D_{\min } / D_{\max }$, the angle from the horizontal to the major axis $\theta$, the hydrometeor cross section $\sigma$ allowing for internal holes, the hydrometeor perimeter $P$, and a dimensionless expression of the hydrometeor complexity

$\chi=\frac{P}{2 \pi r_{\mathrm{eq}}}$

where the equivalent radius $r_{\mathrm{eq}}$ is the radius of an equivalent cross-section circle 


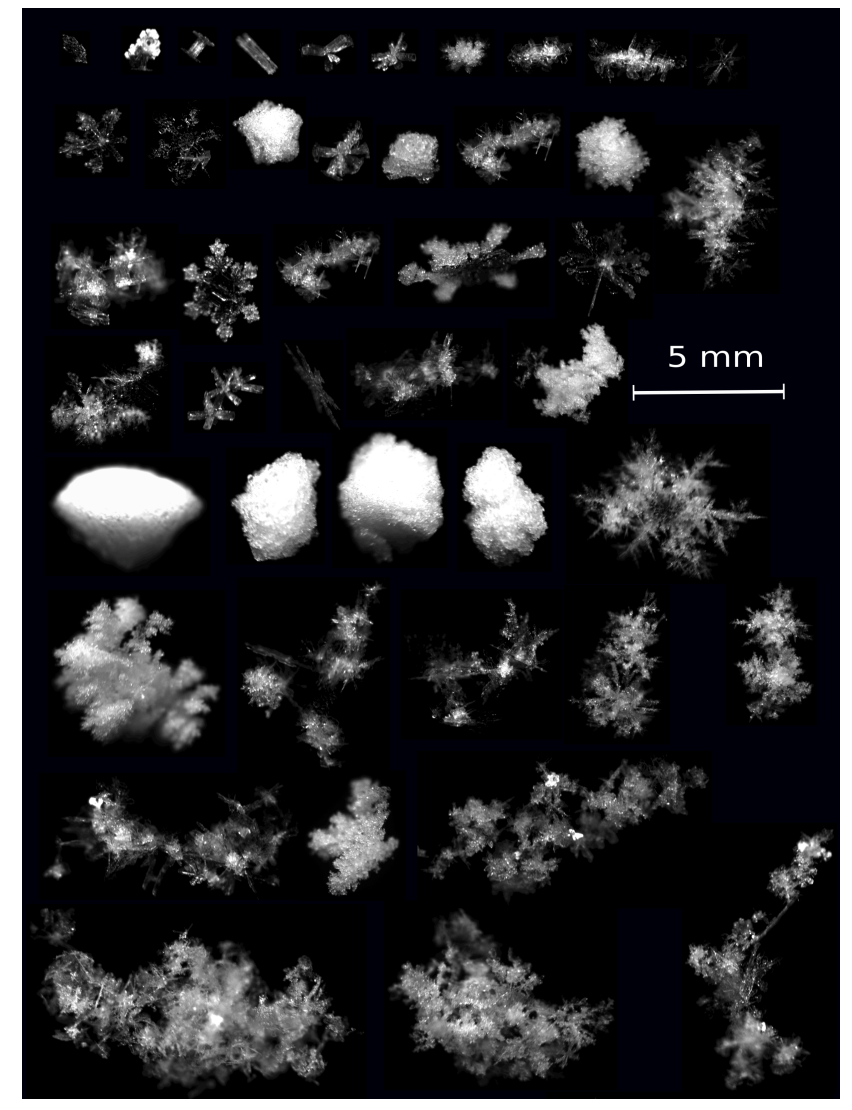

Fig. 2. A sample of MASC images of hydrometeors in free fall taken using a $35 \mathrm{~mm}$ lens on a $5 \mathrm{MP}$ camera.

$r_{\mathrm{eq}}=\sqrt{\sigma / \pi}$.

Thus $\chi=1$ for a spherical particle, is close to unity for quasi-spherical particles such as graupel, and is larger for more complex aggregate shapes. A very crude estimate of hydrometeor mass takes advantage of the multiple camera perspectives:

$m=\frac{4}{3} \pi \rho\left\langle r_{\mathrm{eq}}\right\rangle^{3}$

where $\rho$ is the bulk density of liquid or ice. More sophisticated estimates would account for internal density (Judson and Doesken, 2000; Kajikawa et al., 2004), but this is not known based on MASC measurements alone.

\section{Measurements}

All measurements described here were obtained at an altitude of $2600 \mathrm{~m}$ at the base of Collins Gulch, the uppermost side canyon in Little Cottonwood Canyon, located within the Wasatch Front about twenty miles south of Salt Lake City. The measurement site was outside the home of co-author DH, within the Alta Ski Area bounds. From the base of the
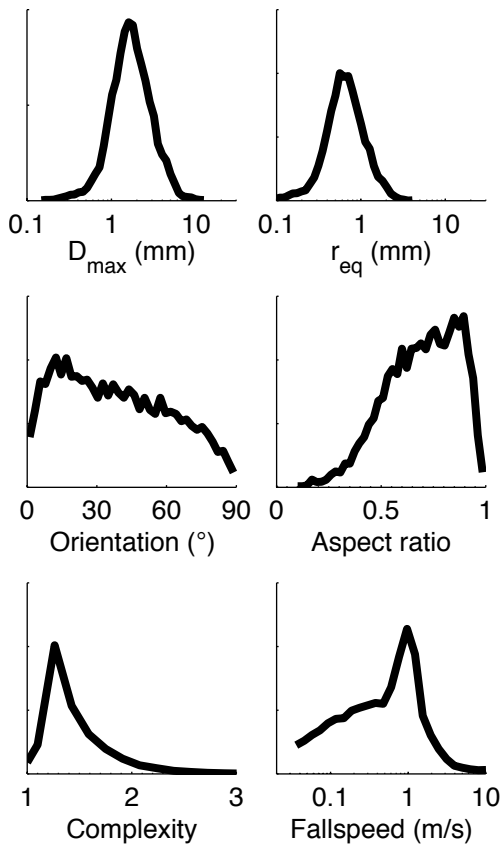

Fig. 3. MASC probability distributions (linear y-scale) based on approximately 10000 images obtained at Alta Ski Area. The dimensionless representation of hydrometeor complexity is defined by the ratio of the hydrometeor perimeter to its equivalent crosssection circumference. For example, the complexity value is unity for a droplet.

ski area, Collins Gulch rises vertically through a depth of $760 \mathrm{~m}$, to the summit of Mt. Baldy at $3350 \mathrm{~m}$ altitude. During storms, prevailing winds are normally up Little Cottonwood Canyon, but Collins Gulch is relatively sheltered compared to the Mt. Baldy ridgeline.

No wind skirt was placed around the MASC, such as those commonly used in precipitation gauge systems. Wind skirts are designed to maximize the efficiency of the catch. However, it has recently been shown that they can also introduce hydrometeor size and shape selection biases (Thériault et al., 2012). Since a wind skirt was not used, what was measured was not necessarily the hydrometeor terminal velocity, but rather a hydrometeor settling speed representing a convolution of the terminal velocity within a turbulent wind field.

The data described here were collected between 10 February and 6 April in 2012. Approximately ten thousand images were obtained that satisfied the conservative rejection criteria outlined in Sect. 3. A small selection of images from the MASC is shown in Fig. 2, chosen to highlight the extraordinary range and complexity of forms that characterize frozen hydrometeors. Hexagonally symmetric forms were observed only very rarely.

From this dataset, Fig. 3 shows probability distributions for maximum dimension $D_{\max }$, equivalent radius $r_{\mathrm{eq}}$, aspect ratio $\alpha$, orientation $\theta$, complexity $\chi$ and fall speed $V$. Median values with lower and upper quartiles for these quantities 


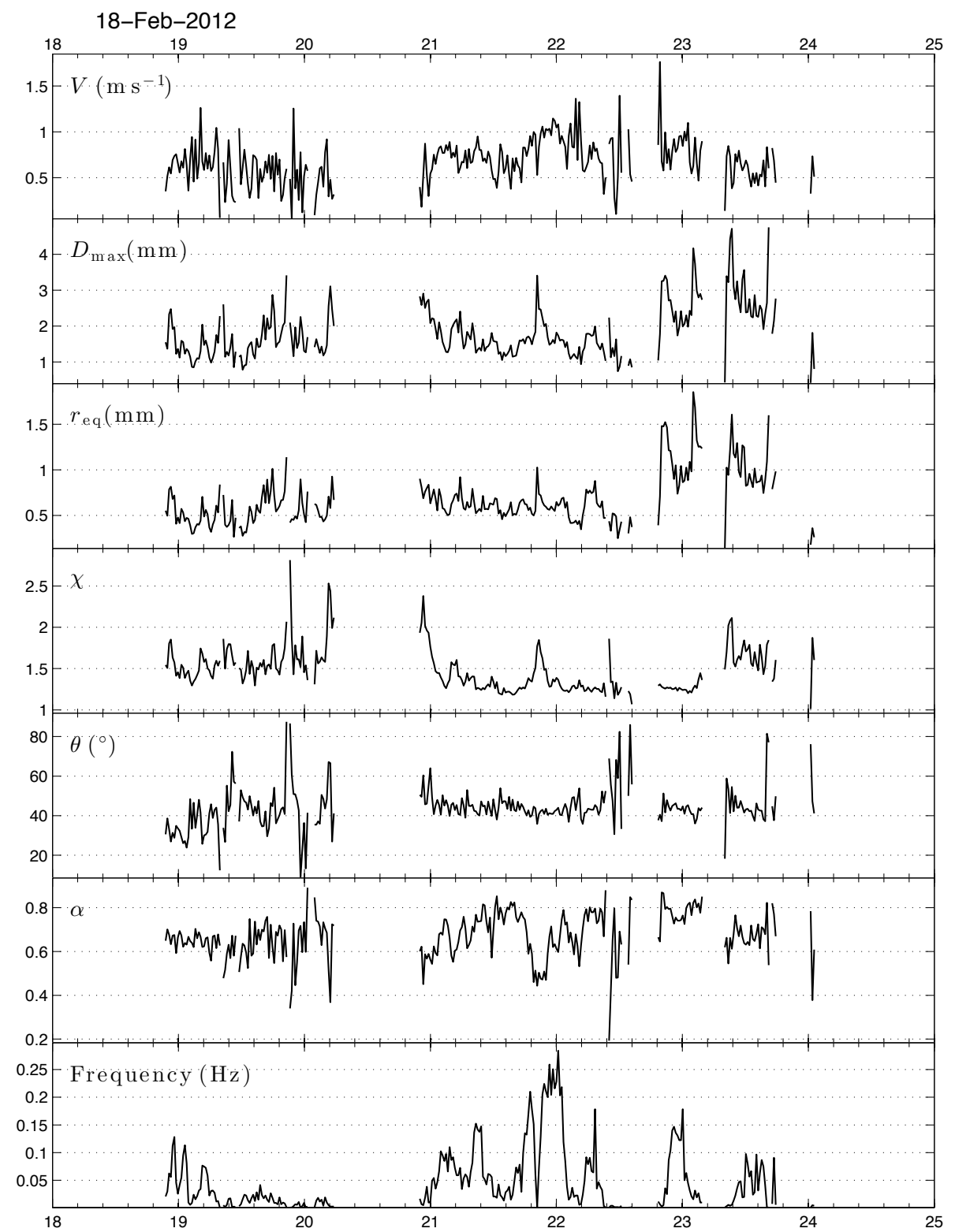

Fig. 4. A time series of analyzed parameters from MASC photography and fall speed data over a one week period beginning 18 February 2012. The timestamp is in MST.

are the following: $D_{\max }=1.7\left[\begin{array}{ll}1.2 & 2.4\end{array}\right] \mathrm{mm} ; r_{\mathrm{eq}}=0.65$ $\left[\begin{array}{ll}0.47 & 0.90\end{array}\right] \mathrm{mm} ; \quad \alpha=0.71\left[\begin{array}{ll}0.57 & 0.83\end{array}\right] ; \quad \theta=36\left[\begin{array}{ll}18 & 56\end{array}\right]^{\circ}$; $\chi=1.2[1.41 .6] ; V=0.53[0.181 .03] \mathrm{m} \mathrm{s}^{-1}$. In general, the size and fall speed measurements are broadly consistent with past measurements of snow that indicate typical linear dimensions of order $1 \mathrm{~mm}$ and fall speeds of order $1 \mathrm{~m} \mathrm{~s}^{-1}$ (Barthazy and Schefold, 2006; Brandes et al., 2007, 2008; Gunn, 1967; Heymsfield and Westbrook, 2010; Magono and Nakamura, 1965; Mitchell et al., 1990; Yuter et al., 2006; Zawadzki et al., 2010). The hydrometeors that were observed tended to have low complexity, with a clear preference for a near unity aspect ratio, suggesting a dominance of riming.
The maximum dimension tended to lie nearer the horizontal than the vertical, although a wide variety of orientations was observed (cf., Xie et al., 2012).

From the dataset that was obtained, Fig. 4 shows a time series of analyzed parameters from over a one week period beginning on 18 February 2012. Mean values are calculated in 20 min blocks provided that there are at least 20 hydrometeors per block that satisfied the aforementioned thresholding criteria. What is notable from the data is that there are periods where there were abrupt changes in some hydrometeor characteristics but not others. For example, late on 21 Feburary, the images showed a mixture of graupel and rimed needles. 
At around 21:00 MST, the same mixture was observed, but the needles became highly aggregated. This abrupt change appears in the time series shown in Fig. 4 as markedly larger and more complex particles. However, there is no coincident transition in fall speed. The reasons for this are unknown but may be related to the absence of a windscreen around the instrument: the settling speed was modified by turbulence in the air.

Also, near midnight on 22 February, there was a graupel event, with large mean particle diameters ranging from 2 to $4 \mathrm{~mm}$. Following a break in the storm, there was a transition to more aggregated shapes in the morning of 23 February. These particles were equally large, but more complex, slower falling, and with a smaller aspect ratio.

\section{Microwave scattering calculations}

MASC data may also be used to refine hydrometeor morphology used as input to microwave scattering calculations. Often, these calculations are done using the discrete dipole approximation method (DDA) (Draine and Flatau, 1994), where the hydrometeor is represented as a dielectric array of electromagnetic dipoles (Liu, 2008a). A popular code for calculating scattering properties is DDSCAT, developed by Draine and Flatau (2008).

DDSCAT calculations can be made for an arbitrary choice of dielectric media and dipole arrangements within the array. The trade-off of this flexibility is that the calculations can be computationally expensive. For sufficient accuracy, the theoretical requirement is that the dipole grid spacing $d$ satisfies Eq. (1), such that $2 \pi|n| d / \lambda<0.5$, where $n$ is the complex refractive index of the hydrometeor, and $\lambda$ is the incident wavelength of the electromagnetic radiation. However, this might easily require over $50 \mathrm{~GB}$ of shared computer memory given that each grid point requires $1 \mathrm{~KB}$ of memory (Draine and Flatau, 2008). As pointed out by Xie et al. (2012), it is normally not worth the expense of making discrete dipole approximation calculations unless a realistic representation of hydrometeor form can be ascertained.

Here, the MASC provides a degree of detail that has not previously been possible, perhaps making DDSCAT calculations worthwhile. To illustrate, triplet stereoscopic snowflake photographs from the MASC are shown in Fig. 5. For microwave scattering calculations (i.e., $\lambda=2 \pi / k>1 \mathrm{~mm}$ and $|n| \sim 1.78$ ), the MASC resolution of 9 or $27 \mu$ m exceeds the degree of detail that is required for making discrete dipole approximation calculations. Further, the MASC provides some representation of the three-dimensional structure of the hydrometeors because it provides an angular perspective spanning $72^{\circ}$. Unfortunately, recreating a full three-dimensional hydrometeor structure remains out of reach, at least for hydrometeors A through C in Fig. 5. Their structure is much too complicated.

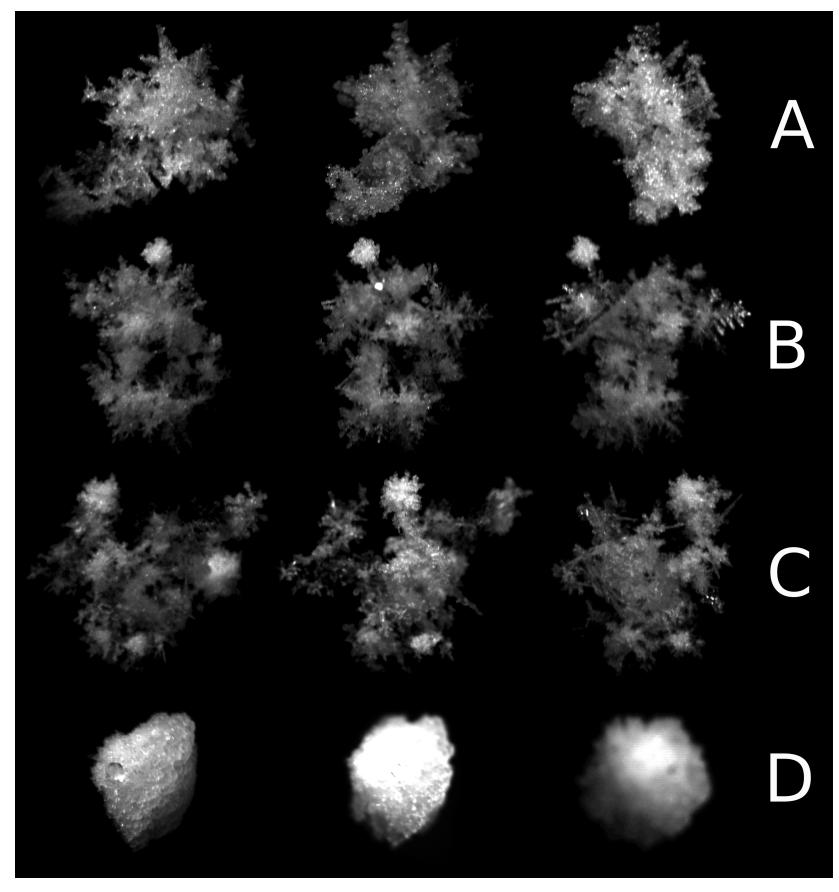

Fig. 5. Triplet stereoscopic images of individual snowflakes imaged with the MASC. The center resolution is $9 \mu \mathrm{m}$ and outside image resolution is $27 \mu \mathrm{m}$.

Nonetheless, a more approximate approach might be the following. The first step is to estimate the volume of the snowflakes from the average equivalent radius for the three projections:

$V=\frac{4}{3} \pi\left\langle r_{\mathrm{eq}}\right\rangle^{3}$.

Second, for each image perspective, the photographed snowflake cross section is extruded normal to the crosssection plane a distance $V /\left(\pi r_{\mathrm{eq}}^{2}\right)$ until its volume is equal to $V$. For example, if the cross section were a hexagonal plate, its extruded form would be a hexagonal column. Here, the shapes are more complicated, so the extruded form might include internal holes that extend through the depth of the extrusion. An example for hydrometeor B in Fig. 5 is shown in Fig. 6.

Third, for each of the three extruded forms, the scattering properties are calculated using DDSCAT, treating the form as an internal mixture of ice and air. The ice is given a refractive index specific to the wavelength of the incident radiation (Warren and Brandt, 2008). Finally, the calculated scattering properties are averaged across perspectives, weighted by the scattering cross section calculated for each camera perspective.

Figure 7 shows calculations for the unpolarized angular scattering matrices (or phase functions) of each of the hydrometeors in Fig. 5, evaluated for an incident frequency of $183 \mathrm{GHz}$, or a wavelength of $1.64 \mathrm{~mm}$. What stands out is 

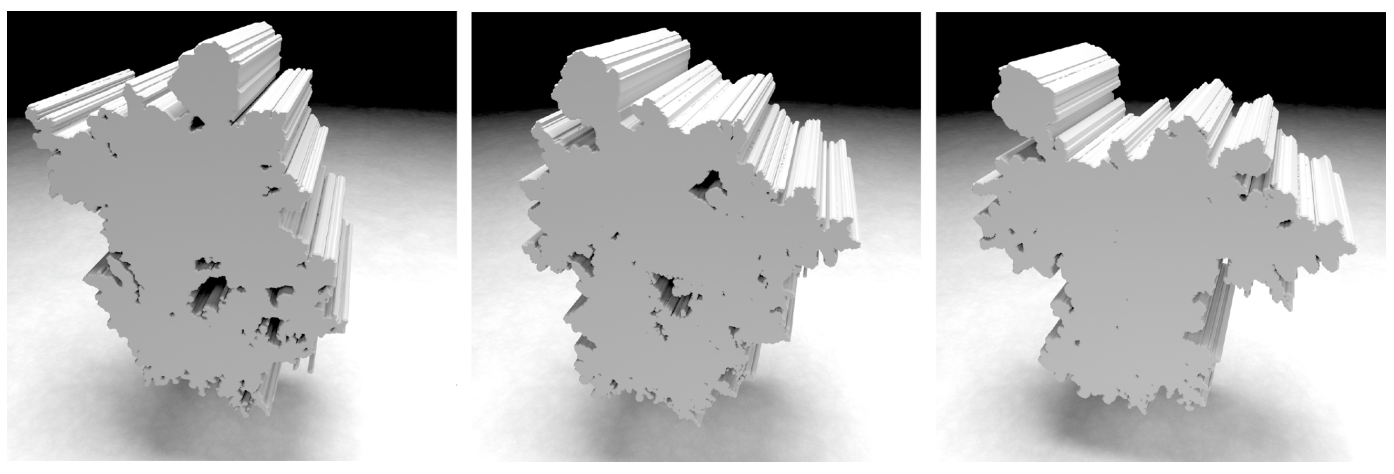

Fig. 6. Example of the triplet form for an extruded ice flake used for input to DDSCAT (hydrometeor B in Fig. 5). Displays are rendered with Monte Carlo ray tracing, based on idealized surface material properties, using a Metropolis sampling method.

that a graupel particle has a much lower scattering efficiency $Q_{\text {sca }}$, and is more strongly biased towards back-scattering than snow particles with a similar volume equivalent effective radius $a_{\text {eff }}=(3 V / 4 \pi)^{1 / 3}$. The differences are particularly marked in the back-scattering regime that matters most to active microwave remote-sensing. A possible explanation is that the components of aggregated ice particles can produce interference patterns that lead to preferential forwardscattering when their separation is small compared to the incident wavelength (Videen et al., 1998).

\section{Conclusions}

This paper has described a new instrument for taking automated, high-resolution, stereoscopic photographs of hydrometeors in free fall while simultaneously measuring their fall speed. The Multi-Angle Snowflake Camera (MASC) resolution is as fine as $9 \mu \mathrm{m}$, and the cameras are triggered by hydrometeors ranging from as small as $100 \mu \mathrm{m}$ up to several centimeters. Three views of each hydrometeor from angles spanning $72^{\circ}$ help to constrain estimates of particle size, shape and orientation. Fall speeds are determined from the time interval between triggers of two vertically separated arrays of infrared motion sensors.

The instrument has been designed to help improve representations of frozen hydrometeors in weather and remote sensing models. Weather model forecasts are sensitive to the details of bulk microphysical parameterizations for hydrometeor form and fall speed. Remote sensing algorithms, particularly those using active and passive signals in the microwave, rest on assumed relationships between the mass of a hydrometeor and its scattering cross section.

Between February and April 2012, continuous measurements were obtained with the MASC at an altitude of $2600 \mathrm{~m}$, in the Wasatch Front near Salt Lake City, UT. This paper has shown time series and statistical distributions collected during this period for such parameters as particle fall speed, size, orientation, aspect ratio and a dimensionless measure of complexity. For each of these parameters,

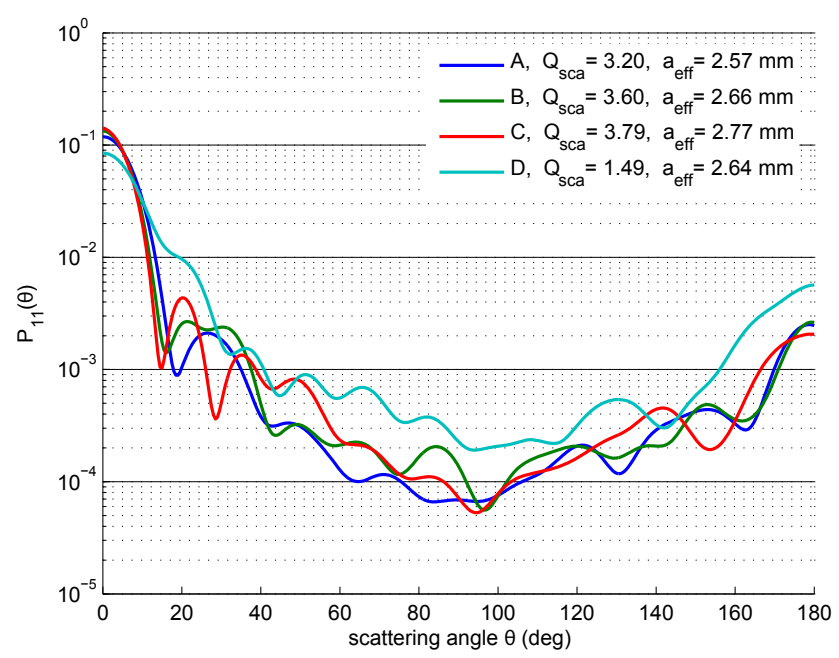

Fig. 7. DDA phase function calculations for the hydrometeors shown in Fig. 5, assuming a mesh of ice and a vacuum for $1.64 \mathrm{~mm}$ wavelength $(183 \mathrm{GHz})$ incident radiation.

a very broad range of values was measured, although we observed a bias towards rounder shapes with an aspect ratio near unity, sizes of about $1 \mathrm{~mm}$, and fall speeds of approximately $1 \mathrm{~m} \mathrm{~s}^{-1}$.

We also show an example of how the high-resolution multi-angle capabilities of the MASC might be used to help constrain discrete dipole approximation computations of the microwave scattering phase function for hydrometeors (Draine and Flatau, 2008). While preliminary, these calculations highlighted the importance of the small-scale details of hydrometeors to their scattering properties. We found that, for particles with a size similar to the microwave wavelength, and with nearly equivalent estimated mass, heavily rimed graupel appears to be more weakly back-scattering and more strongly forward scattering than loosely aggregated snowflake shapes. 
Acknowledgements. The MASC was developed with support from NASA, NSF, the US Army, and the University of Utah Technology Commercialization Office. We disclose that T. J. G. and C. F. are co-owners of Fallgatter Technologies which designs, builds and sells the MASC.

\section{Edited by: S. Malinowski}

\section{References}

Barthazy, E. and Schefold, R.: Fall velocity of snowflakes of different riming degree and crystal types, Atmos. Res., 82, 391-398, 2006.

Barthazy, E., Göke, S., Schefold, R., and Högl, D.: An optical array instrument for shape and fall velocity measurements of hydrometeors, J. Atmos. Ocean. Tech., 21, 1400-1416, doi:10.1175/15200426(2004)021<1400:AOAIFS > 2.0.CO;2, 2004.

Brandes, E. A., Ikeda, K., Zhang, G., Schönhuber, M., and Rasmussen, R. M.: A statistical and physical description of hydrometeor distributions in Colorado snowstorms using a video disdrometer, J. Appl. Meteorol. Clim., 46, 634-650, doi:10.1175/JAM2489.1, 2007.

Brandes, E. A., Ikeda, K., Thompson, G., and Schönhuber, M.: Aggregate terminal velocity/temperature relations, J. Appl. Meteorol. Clim., 47, 2729-2736, doi:10.1175/2008JAMC1869.1, 2008.

Bruintjes, R. T., Heymsfield, A. J., and Krauss, T. W.: An examination of double-plate ice crystals and the initiation of precipitation in continental cumulus clouds, J. Atmos. Sci., 44, 1331-1349, 1987.

Colle, B. A., Garvert, M. F., Wolfe, J. B., Mass, C. F., and Woods, C. P.: The 13-14 December 2001 IMPROVE-2 Event, Part 3: Simulated microphysical budgets and sensitivity studies, J. Atmos. Sci., 62, 3535-3558, doi:10.1175/JAS3552.1, 2005.

Draine, B. T. and Flatau, P. J.: Discrete-dipole approximation for scattering calculations, J. Opt. Soc. Am., 11, 1491-1499, 1994.

Draine, B. T. and Flatau, P. J.: User guide for the Discrete Dipole Approximation Code DDSCAT 7.0, arXiv, available at: http:// arxiv.org/abs/0809.0337v4 (last access: June 2012), 2008.

Garvert, M. F., Woods, C. P., Colle, B. A., Mass, C. F., Hobbs, P. V., Stoelinga, M. T., and Wolfe, J. B.: The 13-14 December 2001 IMPROVE-2 Event, Part 2: Comparisons of MM5 model simulations of clouds and precipitation with observations., J. Atmos. Sci., 62, 3520-3534, doi:10.1175/JAS3551.1, 2005.

Gunn, K. L. S.: The number flux of snow crystals at the ground, Mon. Weather Rev., 95, 921-924, doi:10.1175/15200493(1967)095<0921:TNFOSC > 2.3.CO;2, 1967.

Heymsfield, A. J. and Westbrook, C. D.: Advances in the estimation of ice particle fall speeds using laboratory and field measurements, J. Atmos. Sci., 67, 2469-2482, doi:10.1175/2010JAS3379.1, 2010.

Ishimoto, H.: Radar backscattering computations for fractal-shaped snowflakes, J. Meteorol. Soc. Jpn., 86, 459-469, 2008.

Judson, A. and Doesken, N.: Density of freshly fallen snow in the Central Rocky Mountains, B. Am. Meteorol. Soc., 81, 15771588, 2000.
Kajikawa, M., Goto, H., Kanaya, K., and Kikuchi, K.: Multiple regression equations for the estimation of new snow density from meteorological elements, J. Jpn. Soc. Snow Ice, 66, 561-565, 2004.

Kruger, A. and Krajewski, W. F.: Two-dimensional video disdrometer: a description, J. Atmos. Ocean. Tech., 19, 602-617, 2002.

Lin, Y., Farley, R. D., and Orville, H. D.: Bulk parameterization of the snow field in a cloud model, J. Appl. Meteorol., 22, 1065-1092, doi:10.1175/15200450(1983)022<1065:BPOTSF > 2.0.CO;2, 1983.

Liu, G.: A database of microwave single-scattering properties for nonspherical ice particles, B. Am. Meteorol. Soc., 89, 15631570, 2008a.

Liu, G.: Deriving snow cloud characteristics from CloudSat observations, J. Geophys. Res., 113, D00A09, doi:10.1029/2007JD009766, 2008b.

Locatelli, J. D. and Hobbs, P. V.: Fall speeds and masses of solid precipitation particles, J. Geophys. Res., 79, 2185-2197, doi:10.1029/JC079i015p02185, 1974.

Magono, C. and Nakamura, T.: Aerodynamic studies of falling snowflakes, J. Meteorol. Soc. Jpn., 43, 139-147, 1965.

Maruyama, K.-I. and Fujiyoshi, Y.: Monte Carlo simulation of the formation of snowflakes, J. Atmos. Sci., 62, 1529-1544, doi:10.1175/JAS3416.1, 2005.

Matrosov, S.: Modeling backscatter properties of snowfall at millimeter wavelengths, J. Atmos. Sci., 64, 1727-1736, doi:10.1175/JAS3904.1, 2007.

Milbrandt, J. A., Yau, M. K., Mailhot, J., Bélair, S., and McTaggartCowan, R.: Simulation of an orographic precipitation event during IMPROVE-2, Part 2: Sensitivity to the number of moments in the bulk microphysics scheme, Mon. Weather Rev., 138, 625642, doi:10.1175/2009MWR3121.1, 2010.

Mitchell, D. L., Zhang, R., and Pitter, R. L.: Mass-dimensional relationships for ice particles and the influence of riming on snowfall rates, J. Appl. Meteorol., 29, 153-164, doi:10.1175/15200450(1990)029<0153:MDRFIP>2.0.CO;2, 1990.

Newman, A. J., Kucera, P. A., and Bliven, L. F.: Presenting the snowflake video imager (SVI), J. Atmos. Ocean. Tech., 26, 167179, doi:10.1175/2008JTECHA1148.1, 2009.

Noh, Y.-J., Liu, G., Jones, A. S., and Vonder Haar, T. H.: Toward snowfall retrieval over land by combining satellite and in situ measurements, J. Geophys. Res., 114, D25205, doi:10.1029/2009JD012307, 2009.

Nowell, H. K.: Modeling snow aggregates and their singlescattering properties: Implications to snowfall remote sensing, Master's thesis, Florida State University, Tallahassee, Florida, available at: http://diginole.lib.fsu.edu/etd/2511/ (last access: June 2012), 2010.

Oguchi, T.: Electromagnetic wave propagation and scattering in rain and other hydrometeors, Proc. IEEE, 71, 1029-1078, doi:10.1109/PROC.1983.12724, 1983.

Reisner, J., Rasmussen, R. M., and Bruintjes, R. T.: Explicit forecasting of supercooled liquid water in winter storms using the MM5 mesoscale model, Q. J. Roy. Meteorol. Soc., 124, 10711107, doi:10.1256/smsqj.54803, 1998. 
Rutledge, S. A. and Hobbs, P. V.: The mesoscale and microscale structure and organization of clouds and precipitation in midlatitude cyclones, XII: a diagnostic modeling study of precipitation development in narrow cold-frontal rainbands, J. Atmos. Sci., 41, 2949-2972, doi:10.1175/15200469(1984)041<2949:TMAMSA>2.0.CO;2, 1984.

Skofronick-Jackson, G. M., Kim, M.-J., Wieinman, J. A., and Chang, D.-E.: A physical model to determine snowfall over land by microwave radiometry, IEEE T. Geosci. Remote, 42, 10471058, 2004.

Thériault, J. M., Rasmussen, R., Ikeda, K., and Landolt, S.: Dependence of snow gauge collection efficiency on snowflake characteristics, J. Appl. Meteor. Clim., 51, 745-762, doi:10.1175/JAMC-D-11-0116.1, 2012.

Videen, G., Pinnick, R. G., Ngo, D., Fu, Q., and Chýlek, P.: Asymmetry parameter and aggregate particles, Appl. Optics, 37, 11041109, 1998.
Warren, S. G. and Brandt, R. E.: Optical constants of ice from the ultraviolet to the microwave: a revised compilation, J. Geophys. Res., 113, D14220, doi:10.1029/2007JD009744, 2008.

Westbrook, C. D., Ball, R. C., and Field, P. R.: Radar scattering by aggregate snowflakes, Q. J. Roy. Meteorol. Soc., 132, 897-914, 2006.

Xie, X., Löhnert, U., Kneifel, S., and Crewell, S. L.: Snow particle orientation observed by ground-based microwave radiometry, J. Geophys. Res., 117, D02206, doi:10.1029/2011JD016369, 2012.

Yuter, S. E., Kingsmill, D. E., Nance, L. B., and Löffler-Mang, M.: Observations of precipitation size and fall speed characteristics within coexisting rain and wet snow, J. Appl. Meteorol. Clim., 45, 1450-1464, doi:10.1175/JAM2406.1, 2006.

Zawadzki, I., Jung, E., and Lee, G.: Snow studies, Part 1: A study of natural variability of snow terminal velocity, J. Atmos. Sci., 67, 1591-1604, doi:10.1175/2010JAS3342.1, 2010. 